\title{
Issues and Cause Analysis in Volunteer Management in Chinese Non-profit Organizations
}

\author{
Zhao Junrong \\ The School of Public Management, \\ Yunnan University of Finance and Economics \\ Kunming, P.R.China \\ (zjrong7343@gmail.com)
}

\begin{abstract}
In recent years, Chinese non-profit organizations (NPO) are developed rapidly. They are playing an important role in public management, such as social welfare, environmental protection, and humanitarian assistance. NPOs cannot run well without volunteers, volunteer management is closely related to the organizations' development and the quality of their services. However, from a practical opinion, many NPOs' volunteer management are unprofessional, some defects and shortcomings are still existed. We will discuss the background and necessity of volunteer management in NPOs, and describe the current situation and problems of volunteer management with two cases. Then we will analyze the causes of those problems and briefly made several suggestions.
\end{abstract}

Keywords-Non-profit Organization; volunteer; Human Resource Management

\section{INTRODUCTION}

Non-profit organizations are social organizations that they provide social services not for profit, they are nongovernmental in China [1].

Since the 1990s, various types of China's non-profit organizations developed rapidly. Especially in recent years, these NPOs carried out a lot of social welfare activities as the "third sector", they are becoming more and more important in China's social life, the social influence they made is also growing.

Since the volunteering is one of the special properties of non-profit organizations, government and society strongly advocated the spirit of volunteerism, the number of volunteers and voluntary services are increasing. Volunteer refers to those people who have the spirit of volunteerism, social responsibility and provide services without remuneration [2].

Generally, volunteers were divided into three types according to the work content: some participate in management, some do daily affairs, and some participate the temporary project [1]. The fist type of volunteers usually joins in the council or do as a consultant and participate in decisionmaking; the second one undertakes the daily work just like the ordinary employees in the organization, they supplement the general staff; the third one mainly to participate in or support a short-term activity, their work ended with the end of the event. The latter two types are more common. However, no matter what type of the volunteers, they all have definite rights and obligations.

\section{NeCESSity of VolunteER MANAGEMENT}

Human resource management is one of the internal managements in a non-profit organization. In the personnel structure within the NPOs, volunteers occupy a pivotal position because of the huge number. Therefore, using a standardized approach to manage volunteers effectively can improve the quality of service and promote the sound development of the organization. Specifically, this necessity mainly represents in the following three aspects:

Firstly, volunteers and NPOs survive with each other. NPO is a platform where the volunteers can express their willingness to serve the community and reflecting their social value; on the other hand, they are an indispensable human resource that NPOs need them to carry out the activities successfully, volunteers can embody the spirit of organizations' services [2].

Secondly, volunteers usually provide voluntary services without remuneration, but this " remuneration " does not mean completely unrequited, it also doesn't mean that the organizations can use volunteers unconditionally. In the course of volunteer service, volunteers must be respected and humane cared, they have the access to get training opportunities and some benefits as same as the regular employees. From this perspective, only a formal rational volunteer management method can achieve respect for volunteers, only in this way can meet the needs of both organizations and volunteers.

Thirdly, having a large number, unstable and unprofessional are three features of volunteers, a standardized management work can help to prevent confusion, reduce error rates, ensure the implementation of the project and also ensure the efficient operation of the organization.

\section{VolunteER MANAGEMENT Situation IN NPO}

Although volunteer management is very important for NPOs, it is not taken seriously by most NPOs in China, problems and defects are still existed in some organizations. 


\section{A. The situation}

For now, the volunteer management is roughly divided into two modes, one is self-management mode, another one is outsourcing mode.

In the self-management mode, organizations do the volunteer recruitment, training and management by themselves. This is the way the most organizations are taken, especially for the mature and big organizations. This approach is quite direct, the communication is simple and effective between volunteers and their supervisor, it is easy to match supply and demand. However, it is easily lead to irregularities in some grassroots organizations in this mode.

For example, two patients organized a rare disease patient care association in Beijing and manage it by themselves, it aims to provide medical assistance and social support for a number of rare diseases sufferers. Due to lack of staff, they need a lot of volunteers, they choose to contact with volunteers on internet go through a QQ group (QQ is China's most widely used chat software). They publish a notice on QQ when they need volunteers. Supervisors and volunteers cannot meet face to face, it is not convenient to coordinate the number and time of volunteers, the archives of volunteers can hardly be established.

Some other smaller agencies that not mature enough usually use the outsourcing mode. Taking a social work office in Shanghai as an example. This firm is committed to youth community service. They recruited volunteers from another volunteer service center. The center plays a mediating role then provide volunteers to the office regularly. This mode can reduce the burden on organizations, but easily leads to the situation that volunteers' major doesn't match the position demand, the agency is in a passive position on arranging volunteers.

So, no matter which mode we take, the specification should be placed first, otherwise, both the enthusiasm of volunteers and the agencies' working efficiency will be affected.

\section{B. Volunteer management issues}

According to the above examples, from a point of view of managers, volunteer management problems mainly existed in the following three aspects.

1) Management process is too casual. Volunteer management involves many aspects, including work content analyzing, planning, recruiting, training, instructing, evaluating and encouraging, this is a complete process. Most agencies only manage the recruitment, training and activity guidance, but the work content analyzing, evaluating and encouraging are neglected.

2) Volunteers turnover seriously, voluntary services are lack of continuity. Most volunteers only participate in shortterm projects, few of them would remain in the institution after a service completed. There are even fewer people can be reused by administrators for a long time. At the same time, there are not so many long-term projects or jobs can attract the volunteers to stay in one organization. There is no fixed group of volunteers bring about the mount of agency costs in recruitment and training.

3) Volunteers are difficult to assimilate into the organization, their sense of achievement is not high. Many volunteers engaged in low-tech jobs, it is difficult to play their enthusiasm and initiative. Their proposals are ignored sometimes, they are always in a passive and edge position. Organizations are failing to make use of volunteers' specialty then leads to the waste of human resources.

\section{Problems Cause Analysis}

A. From a macro point of view, economic base is an important reason. Generally speaking, the funding voluntary service comes from government investment, corporate donations, charity granting, volunteer contributions and self-employed income [2]. The overall level of China's economic is growing underdeveloped, the government plays a limited role, so the fund of NPOs can obtain is limited. As a result, the sum of money that invested in volunteer management is not enough. Economic lag is difficult to provide adequate funding for the voluntary service.

$B$. It is hard to find a professional volunteer administrator. Most administrators of the grassroots organizations are lack of a clear understanding on volunteer management. When facing the volunteers with different background, different major and different lever, administrators often see them as the same type of people, so they cannot carry out a targeted management and there no flexible incentives. An inefficient or a chaotic management will reduce the enthusiasm self-realization of volunteers. At the same time, the agencies and volunteers cannot communicate clearly without a fixed standardized management approach.

C. Administrators do not pay attention to volunteer management. NPOs are developing rapidly and they have huge potential in today's China, so the administrators are committed to the survival and development of the agency to strive to occupy a dominant position. In their objectives and the actual operation, volunteers are ignored, the human resource management of volunteers is placed at the edge. Because paying no attention to the volunteer management, there are drawbacks.

$D$. Reasons in volunteers themselves. With the increasing number of volunteer activity and the initiative of the state, the quality of volunteer service is not good enough, the purpose of the volunteers has becoming not simple. Under the driven by various benefits, some volunteer services are often carried out on memorial days or holidays, volunteers aim to complete the task and get a prize, they did not really help the clients. 


\section{Measures to Change the Situation}

Volunteer human resource management is a complex science, it is necessary to change the concept of administrators, but also to improve the system.

In concept, administrators should have a profound understanding about volunteer management, they should treat a volunteer as a helpful person to the organization instead of the free labor. Volunteers are the people with lofty spirit, they have dignity and right, they need support and reward, and they are a strong power to NPOs' survival and development. Only by changing the attitude to the volunteers can complete the management of volunteers.

Institutionally, a specific, reasonable and humane system must be established. Volunteer management cannot be limited in daily management, it should also be extended to the preparation before an activity and the evaluation after the activity. During the management process, administrators must be carefully strict and flexible, they should punish the inappropriate behaviors or support meaningful actions.

It is not difficult to see that both administrators and volunteers should pay attention to enhance their own capabilities. Improving the management capacity and expertise, guiding volunteers to understand their responsibilities and targets are quite necessary for administrators. It is an art to let volunteers show their specialties in the service process. Nonprofit organizations are serving for the community, they are also serving for the volunteers, this is the starting point and foothold for a non-profit organization to develop its volunteer human resources management strategy [3].

\section{REFERENCES}

[1] Wang ming. Nonprofit Organization Management Introduction [M]. Press of Renmin University of China, 2010. (In Chinese)

[2] Fan Jine, Li Ou. A rational Perspective on the missing of humane environment in volunteer resource development [J]. Journal of Changchun University of Technology (Social Sciences Edition), 4, 2004. (In Chinese)

[3] Zhu Xiang, Yu Jiaqi. Strategies of volunteer management in non-profit organizations [J]. Theory Horizon, 6, 2009. (In Chinese)

[4] Fisher J.C.\& Cole K.M. Leadership and management of Volunteer programs : A guide for volunteer administrators San Francisco [M]. Jossey-Bass Publishers, 1993.

[5] Henry B. Hansmann. The Role of Nonprofit Enterprise[J]Yale Law Journal, 1980.

[6] Giacomo Manetti, Marco Bellucci, Elena Como, Luca Bagnoli.Investing in volunteering: measuring social returns of volunteer recuitment, training and management[J]International Journal Voluntry and Nonprofit Organizations, 2014. 